\title{
Optimization of reaction conditions for preparing carboxymethyl cellulose from sago waste
}

\begin{abstract}
Sago pulp (57\% w/w) isolated from sago waste was converted to carboxymethyl cellulose (CMC) by etherification using sodium monochloroacetate and sodium hydroxide. The reaction was optimized against temperature, concentration and reaction time. The optimized product has a large degree of substitution (DS) of 0.821, which compared favorably to other forms of cellulose. Fourier Transform Infrared spectra (FTIR) were used to characterize the product and starting sago pulp. Digital photographs of sago waste and sago pulp showed the expected rough woody structure while that of the CMC generated from the pulp showed a smooth surface morphology.
\end{abstract}

Keyword: Sago waste; Sago pulp; Carboxymethyl cellulose; Carboxymethylation; FTIR 